\title{
Study on Mechanical and Physical Behaviour of Hybrid GFRP
}

\author{
Nor Bahiyah Baba, Ahmad Syakirin Suhaimi, \\ Muhamad Asyraf Mohd Amin, and Alias Mohd \\ Department of Manufacturing Engineering Technology, TATI University College (TATIUC), 24000 Kemaman, Terengganu, Malaysia
}

Correspondence should be addressed to Nor Bahiyah Baba; bahiyah@tatiuc.edu.my

Received 9 April 2015; Revised 26 June 2015; Accepted 28 June 2015

Academic Editor: Stefano Sorace

Copyright (c) 2015 Nor Bahiyah Baba et al. This is an open access article distributed under the Creative Commons Attribution License, which permits unrestricted use, distribution, and reproduction in any medium, provided the original work is properly cited.

\begin{abstract}
The paper discusses the mechanical and physical behaviour of hybrid glass fibre reinforced plastic (GFRP). Hybrid GFRP was fabricated by three different types of glass fibre, namely, 3D, woven, and chopped, which were selected and combined with mixture of polyester resin and hardener. The hybrid GFRP was investigated by varying three parameters which were the composite volume fractions, hybrid GFRP arrangement, and single type fibre. The hybrid GFRP was fabricated by using open mould hand lay-up technique. Mechanical testing was conducted by tensile test for strength and stiffness whereas physical testing was performed using water absorption and hardness. These tests were carried out to determine the effect of mechanical and physical behaviour over the hybrid GFRP. The highest volume fraction of 0.5 gives the highest strength and stiffness of $73 \mathrm{MPa}$ and $821 \mathrm{MPa}$, respectively. Varying hybrid fibre arrangement which is the arrangement of chopped-woven-3D-woven-chopped showed the best value in strength of $66.2 \mathrm{MPa}$. The stiffness is best at arrangement of woven-chopped-woven-chopped-woven at $690 \mathrm{MPa}$. This arrangement also showed the lowest water absorption of $4.5 \%$. Comparing the single fibre type, woven had overtaken the others in terms of both mechanical and physical properties.
\end{abstract}

\section{Introduction}

Glass fibre reinforced polymers (GFRP) have been intensively studied by the researchers as they have many applications in industry such as structural component, storage tanks, and automotive application and also in concrete $[1,2]$. Furthermore, GFRP tends to have advantage from economical view [3]. GFRP is categorised under polymeric composite in which polymer resin acts as the matrix and is later reinforced by glass fibre. The addition of filler into the polymer matrix resulted in excellent mechanical and physical properties in the GFRP composite.

Hybrid composite is the reinforcement of a common matrix by two or more types of fibre. The essential objective for developing this type of composite is to possess the advantages of its constituents [4].

Hybrid composites are more advanced composites as compared to conventional FRP composites. Hybrids can have more than one reinforcing phase and a single matrix phase or single reinforcing phase with multiple matrix phases or multiple reinforcing and multiple matrix phases. They have better flexibility compared to other fibre reinforced composites. Usually they combine a high-modulus fibre with the one on low modulus fibre. The high-modulus fibre provides the stiffness and load bearing qualities, whereas the low-modulus fibre makes the composite more durable and low in cost.

The mechanical properties of a hybrid composite can be varied by changing volume ratio and stacking sequence of different plies [5]. Previous works on hybrid of E-glass fiber/Kevlar 29 fiber in polyester resin showed that the hybrid composite performed better at high impact velocity than the monolithic glass fibre composite [6]. There are studies done on innovative FRP of rheoplastic and recycled PET fibre in mortar or concrete that significantly enhanced the flexural strength and toughness of the composite [7-9].

Fabrication processes of GFRP have undergone substantial evolution in recent years. Although the traditional hand lay-up process remains the process of choice for some applications, new developments in pultrusion, resin transfer 
TABLE 1: GFRP hybrid fibre arrangement of layer L1-L5.

\begin{tabular}{cccccc}
\hline$\#$ & L1 & L2 & L3 & L4 & L5 \\
\hline 1 & A & C & B & C & A \\
2 & B & C & A & C & B \\
3 & C & A & B & A & C \\
4 & C & B & A & B & C \\
5 & A & C & A & C & A \\
6 & B & C & B & C & B \\
\hline 3D (A), woven (B), and chopped (C). & & &
\end{tabular}

TABLE 2: Type of glass fibre.

\begin{tabular}{lcc}
\hline Sample & Fibre & Number of layers \\
\hline 1 & $3 \mathrm{D}$ & 3 \\
2 & Woven & 3 \\
3 & Chopped & 3 \\
\hline
\end{tabular}

moulding, vacuum infusion, sheet moulding compound, low temperature curing prepregs, and low pressure moulding compounds are taking the industry to new level of sophistication and are now being exploited in high technological areas [10]. Right fabrication technique depends mostly on the properties of the resins; for example, lower viscosity resins have higher tendency to penetrate in clothing, thus suitable for open mould technique [11].

This current study will contribute to the mechanical and physical properties of hybrid GFRP which has varying layer of fibre types and arrangement. The main parameters such as fibre volume fraction and fibre arrangement in each layer were fabricated using open mould hand lay-up process. Testing involves tensile for mechanical studies but water absorption and hardness test for physical studies.

\section{Experiment Details}

2.1. Materials. The main materials for the study are various types of fibre glass and polymer resins. There are several types of fibre glass and matrix used to fabricate hybrid GFRP, which are the $3 \mathrm{D}$, woven, and chopped strand mat. Polymer matrix used is polyester resin and its hardener.

2.2. Composition. The experiment was divided into three parameters according to hybrid GFRP fibre volume fraction, hybrid GFRP fibre arrangement and single type fibre.

In varying the hybrid GFRP fibre arrangement, the fibre volume fraction was kept constant at 0.3 . Six different fibre arrangements were identified and three specimens were tested using Instron machine and water absorption test. The arrangement of fibre was identified by varying different types of glass fibre in each layer as shown in Table 1 .

2.3. Single Type Fibre. A single type fibre means only one type of glass fibre was used at 0.3 volume fraction. This parameter acts as a standard and the fabrication was carried out by adding up layer by layer of single fibre to the process. There

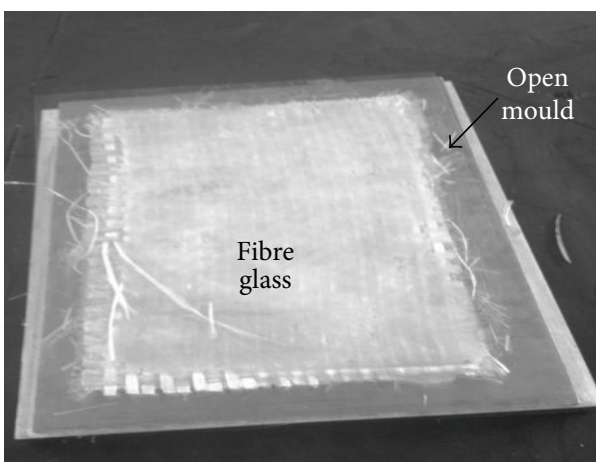

FIgURE 1: Open mould filled up with fibre glass in hand lay-up process.

are 3 types of single fibre used, i.e. 3D, woven and chopped (Table 2).

2.4. Hand Lay-Up Process. Both glass fibre and polyesterhardeners weighed accordingly to its respective volume fraction. Polyester resin and hardener were mixed well. The intensive observant was taken during stirring and mixing process to avoid formation of air bubbles. The air bubbles trapped in matrix resin may result in defect within the GFRP.

Open mould aluminium alloy was fabricated by CNC machines (CNC 10-HVA). Glass fibre was placed in the mould followed by adequate layer of matrix resin and the process was repeated until the layers were completed (Figure 1). Each layer was properly rolled to ensure no air was entrapped within the layer.

2.5. Tensile Test. Tensile testing determines most important mechanical properties of the material. It is the ability of material to withstand force pulling its part. Tensile properties were measured with Instron Machine 3382. Crosshead speed was set to $5 \mathrm{~mm} / \mathrm{min}$ and data was processed in computerized Blue Hill 3 software.

There are two parameters varied, that is, volume fraction and hybrid arrangement, that were represented by three samples each. Hence, there were 36 dumb-bell shaped samples produced for the tensile testing in accordance to the ASTM 412 as shown in Figure 2.

Water absorption tests were conducted according to ASTM D 570-99. The Hybrid GFRP was cut into three rectangular shaped specimens with a dimension of $20 \mathrm{~mm} \times$ $20 \mathrm{~mm} \times 5 \mathrm{~mm}$. The samples were dried at $60^{\circ} \mathrm{C}$ for 24 hours to reach at the constant weight.

According to ASTM 2240, hardness is the resistance of a material to permanent indentation. Hardness is an empirical test and therefore it is not a material property. Shore durometer-D is used to measure the hardness of the material.

\section{Results and Discussion}

3.1. Volume Fraction. The hybrid GFRP fibre volume fraction varied in the ranges between 0 and $0.5 \mathrm{vf}$. The load-extension diagrams for 0 and $0.5 \mathrm{vf}$ produced by Blue-Hill 3 software 


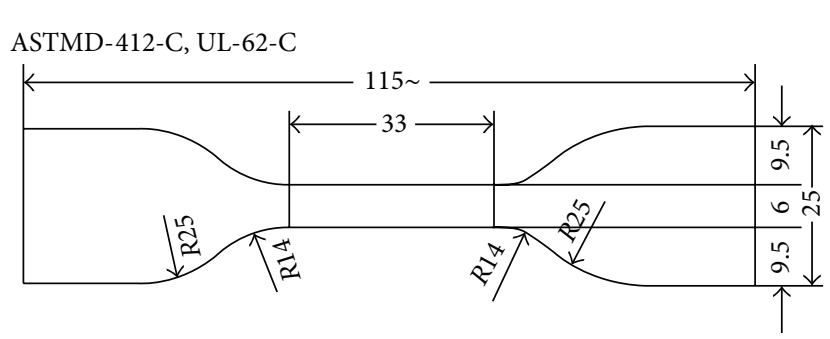

(a)

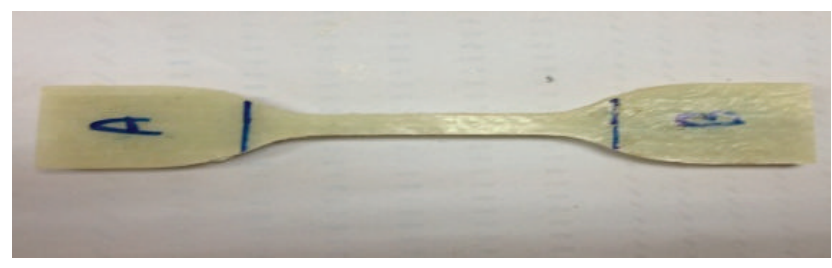

(b)

Figure 2: Testing dumbbell shape (a) ASTM D-412 type C and (b) hybrid GFRP.

are shown in Figure 3. The trends of both diagrams shared similar trend for all of the three specimens tested. The ranges of maximum load for 0 volume fraction are between 18 and $25 \mathrm{~N}$ whereas for volume fraction 0.5 is between 2000 and $2500 \mathrm{~N}$. Increasing amount of reinforcement in the matrix definitely makes the composite stronger by a factor of 100 .

In mechanical characteristics, the most important mechanical properties are the strength and modulus. Figure 4 shows the mechanical properties of hybrid GFRP at different fibre volume fractions. Both mechanical properties of tensile strength and Young's modulus of hybrid GFRP increase gradually as the fibre volume fraction increases. The highest value for tensile stress is at $0.5 \mathrm{vf}$ at $73 \mathrm{MPa}$ and the lowest value is at $0 \mathrm{vf}$ of only $0.71 \mathrm{MPa}$.

Similarly, the Young's modulus of hybrid GFRP increases as the fibre volume fraction increases. The graph illustrates the highest value of $0.5 \mathrm{vf}$ achieved at $821 \mathrm{MPa}$ and the lowest value of elastic modulus is at $4.8 \mathrm{MPa}$ for $0 \mathrm{vf}$.

This indicates the more fibres added to the hybrid GFRP the stronger and stiffer the composite becomes. Fibre glass acts as the reinforcement to the polyester resin matrix which the matrix holds the fibres together and thus it strength is enhanced by the fibre pull out effect [12]. However, adding too large amount of fibre will cause lacking of matrix to hold the fibre together and reduces its strength and stiffness. Therefore, adding more fibre up to half of the total volume has positive effect on both tensile strength and Young's modulus.

It is known that adding more reinforcement to the matrix will increase the mechanical properties and the results discussed above reflect such expected behaviour. In terms of physical properties, the water absorption and hardness SD-D of the hybrid GFRP data as well as their standard deviation values are tabulated in Table 3 . The data presented in Table 3 shows that as the volume fraction of glass fibre reinforcement increases to 0.5 , both water absorption and hardness increase by $10 \%$ and $16 \mathrm{SD}-\mathrm{D}$, respectively.

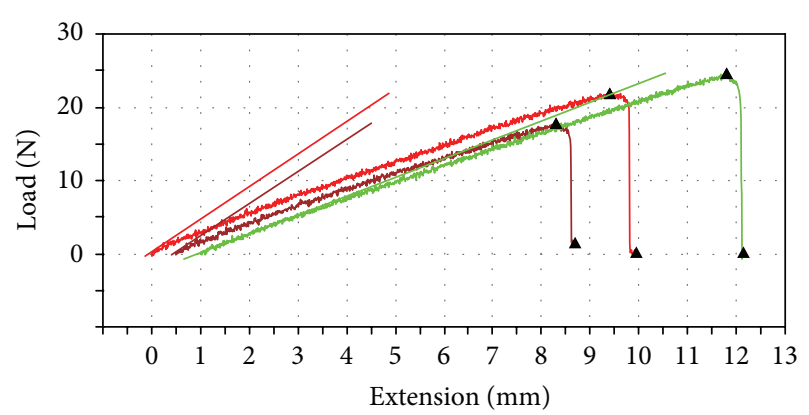

Specimen \#

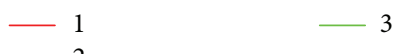

(a)

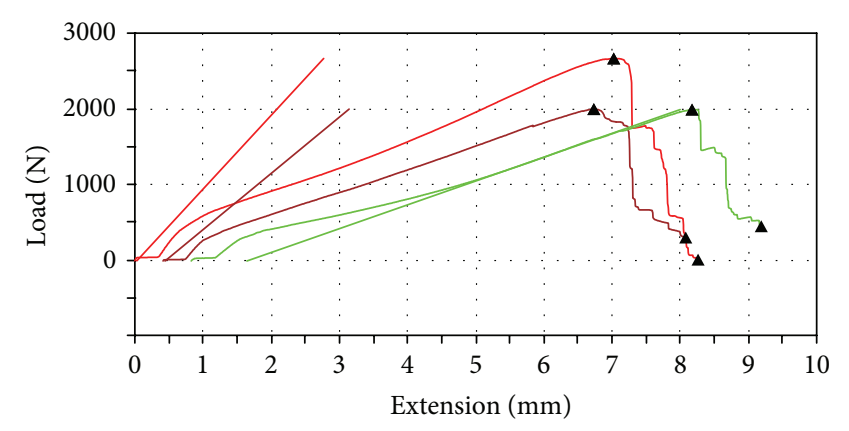

Specimen \#

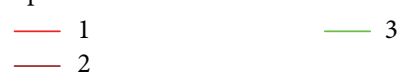

(b)

Figure 3: Load-extension diagrams at volume fraction at (a) 0 and (b) 0.5 .

TABLE 3: Water absorption (WA) and hardness (SD-D) data and their standard deviation (std. dev.).

\begin{tabular}{lcccc}
\hline $\begin{array}{l}\text { Volume } \\
\text { fraction }\end{array}$ & $\begin{array}{c}\text { Average } \\
\text { WA/\% }\end{array}$ & Std. dev. & $\begin{array}{c}\text { Average } \\
\text { SD-D }\end{array}$ & Std. dev. \\
\hline 0 & 1.45 & 0.12 & 19.1 & 0.91 \\
0.1 & 5.17 & 0.16 & 19.7 & 0.52 \\
0.2 & 5.35 & 0.18 & 23.1 & 0.26 \\
0.3 & 7.34 & 0.73 & 29.7 & 0.96 \\
0.4 & 9.10 & 0.29 & 31.53 & 0.70 \\
0.5 & 11.67 & 0.34 & 35.43 & 0.68 \\
\hline
\end{tabular}

Physical properties of hybrid GFRP against varying volume fraction are shown in Figure 5. Both water absorption and shore durometer- $\mathrm{D}$ increase when volume fraction of the hybrid fibre was raised from 0 to $0.5 \mathrm{vf}$. The water absorption of composites increases gradually as the fibre volume fraction increases. As the fibre content increases, the formation of fibre agglomerations increases due to the difficulties of achieving a homogeneous dispersion of filler at high fibre content. The agglomeration of the filler in composites absorbs large amount of water in the composites [13]. 


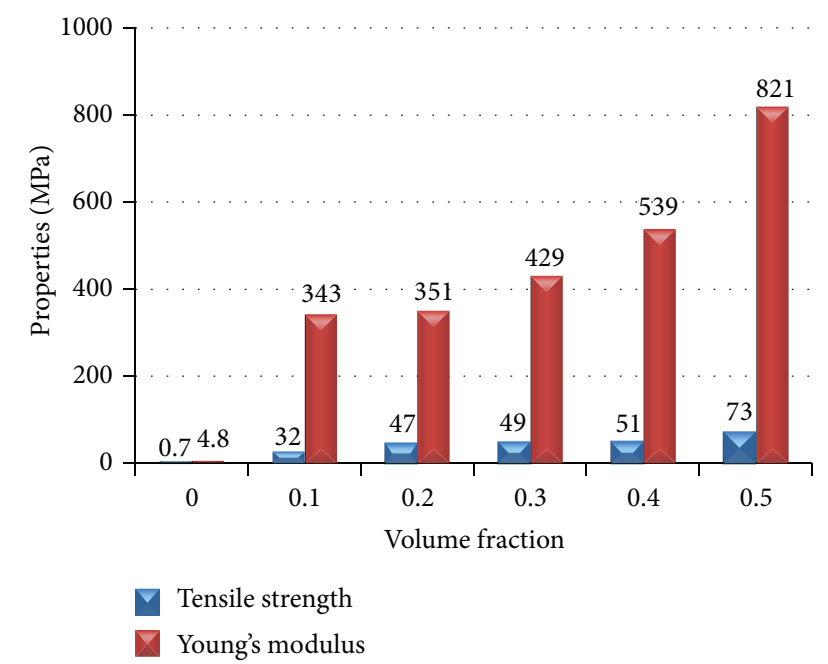

FIGURE 4: Mechanical properties of hybrid GFRP varying fibre volume fraction.

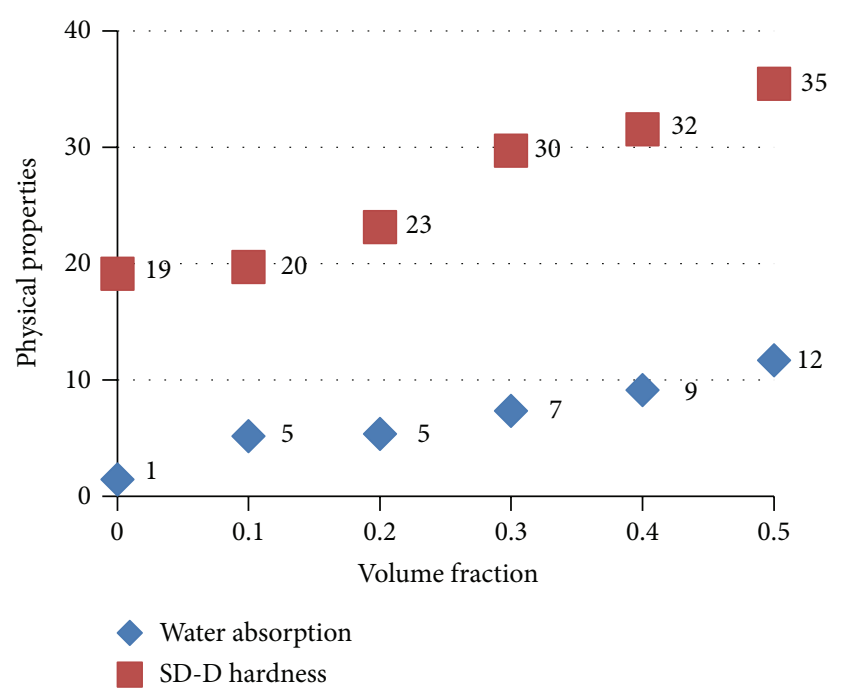

FIGURE 5: Physical properties at varying volume fraction.

As for the value of hardness SD-D, the highest value of 35 SD-D is at $0.5 \mathrm{vf}$ and $19.1 \mathrm{SD}-\mathrm{D}$ is at $0 \mathrm{vf}$. It is clearly shown that surface hardness of the composite strongly depends on the amount of fibre. Hence, it is obvious that, SD-D hardness increases with the increment fibre content and this behaviour is highly expected [14].

3.2. GFRP Hybrid Fibre Arrangement. Hybrid GFRP fibre arrangement is about varying layers of glass fibre in the composite as shown in Table 1. The systematic arrangement of the fibre can give high strength and stiffness to the composite. Hence, the suitable choice of fibre types in the arrangement layer (top, middle, and bottom) has to be determined rigorously.

The tensile strength and Young's modulus of all the six layers of hybrid fibre arrangement are shown in Figure 6. It had been discovered that the highest value of tensile strength

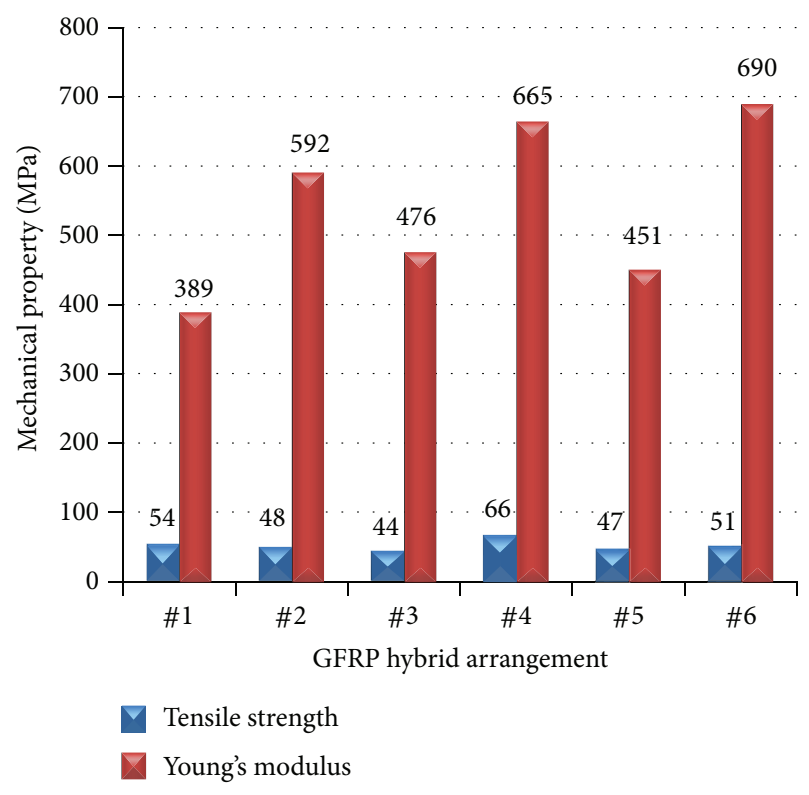

FIGURE 6: Mechanical properties of hybrid GFRP fibre arrangement.

is at $66 \mathrm{MPa}$ obtained by arrangement \#4. On the other hand, the lowest value is $44 \mathrm{MPa}$ for arrangement \#3, whereas, the highest value of Young's modulus is with arrangement \#6 at $690 \mathrm{MPa}$ and the lowest for arrangement \#1 is at $389 \mathrm{MPa}$.

The 3D type is more compatible to use at the middle of the layers because its thickness is thicker than the others. This behaviour is supported by the results of arrangement \#2 and \#5. The chopped fibres at the top and bottom layer strengthen the composite by fibre pull-out and its random orientation produces an anisotropic behaviour. Woven layers can support other layers to obtain balance and strong structure [15]. Woven gives solid and dense structure compared to the 3D and chopped type. The Young's modulus trend was dissimilar to the results of tensile strength. However, the trend was not contradicted. The highest stiffness was achieved by 3 alternating layers of woven fibre. Following closely behind is arrangement \#4 which has the highest strength.

Figure 7 shows the result of water absorption varying hybrid fibre arrangement of GFRP. From the observation, the highest value of water absorption is for arrangement $\# 5$ with $7.1 \%$ whereas the lowest value is for arrangement \#6 with $4.5 \%$. This might be due to the strong effect of the types of fibre.

Arrangement \#6 consists of two layers of chopped and three layers of woven type. It is obviously shown that two arrangements, \#4 and \#6, have advantages to avoid water absorption compared to the other arrangements because woven and chopped are more dense compare to the others. These phenomena reduce air entrapment and amount of voids in the matrix compared to the $3 \mathrm{D}$. A proper fabrication method should be considered in future works.

3.3. Single Type Fibre. Three samples of each single fibre types, namely 3D, woven, and chopped, were tested. The results were taken from the average of three specimens in each 


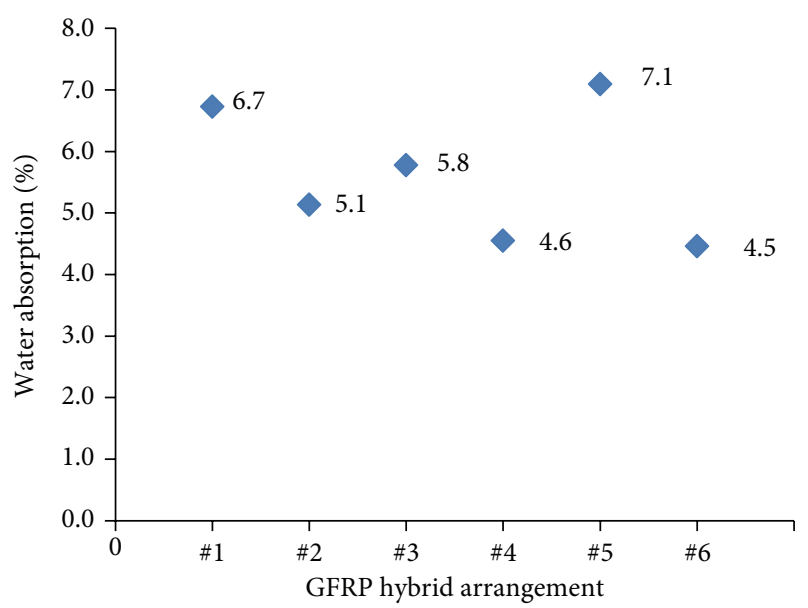

FIGURE 7: Water absorption for varying hybrid GFRP fibre arrangement.

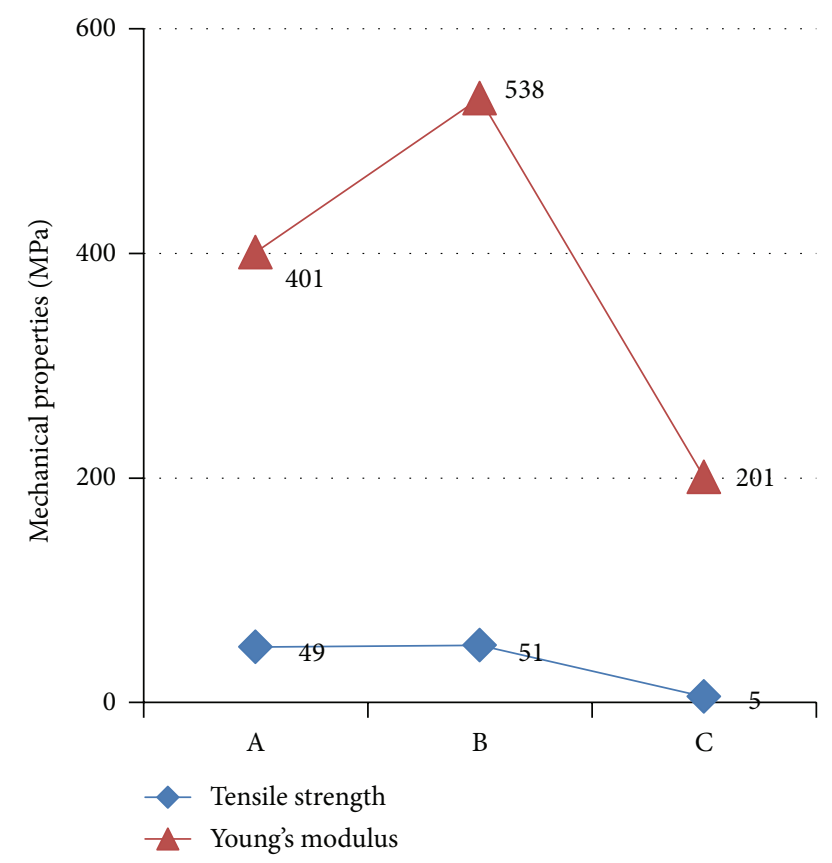

FIGURE 8: Hybrid GFRP mechanical properties of the three single type fibre.

single fibre type. Figure 8 shows the result of hybrid GFRP mechanical properties for varying single type fibre.

The trend of mechanical properties, tensile strength, and Young's modulus was found similar. The highest value is obtained by the woven type at $51 \mathrm{MPa}$ and $538 \mathrm{MPa}$ for strength and stiffness, respectively. These were followed very close behind by the $3 \mathrm{D}$ type at $49 \mathrm{MPa}$ and $401 \mathrm{MPa}$, respectively.

Eric Greene Associates (2003) found that 3D is a new technology combining with woven and chopped structure and $3 \mathrm{D}$ is the best type compared with chopped and woven in mechanical strength, light weight, and special interstitial structure [16]. However, in this study, contradicting finding

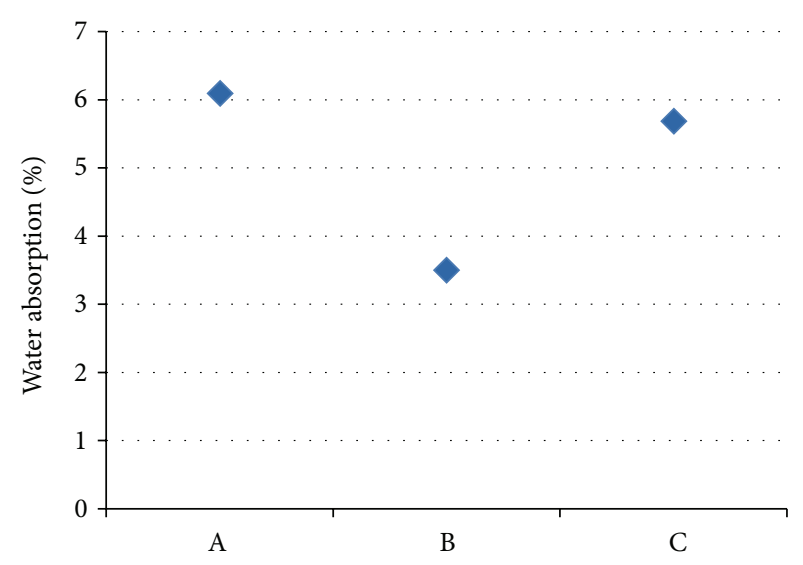

FIGURE 9: Water absorption of three single type fibre.

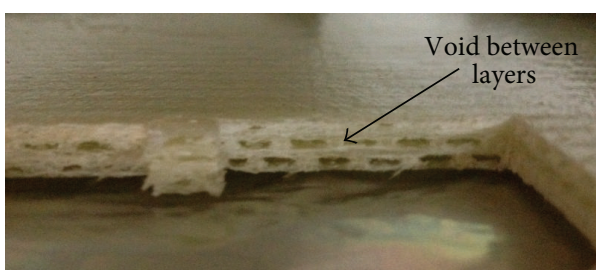

(a)

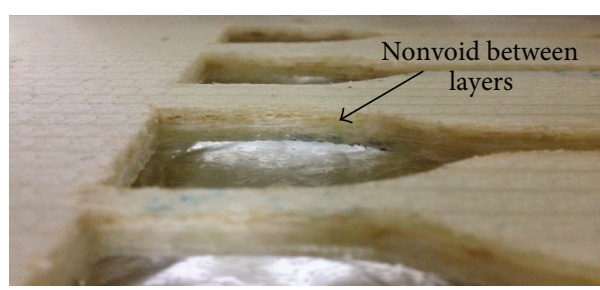

(b)

FIGURE 10: Hybrid GFRP structure between layers for (a) 3D and (b) woven.

was obtained. The woven has higher strength and stiffness compared to the 3D type. This might due to the presence of voids in the structure. Voids strongly affected the mechanical properties of a composite [17].

The structure of each single fibre type of GFRP caused the different results in the graph. Woven type has the highest value of modulus because it has a rigid and dense structure. Apart from that the mat interlocking arrangement gives more advantages especially in terms of anisotropic behaviour [9]. $3 \mathrm{D}$ has low tensile strength due to void in their structure, all at once affected their elastic modulus. The lowest strength was obtained by the chopped type at $5.5 \mathrm{MPa}$ and $201 \mathrm{MPa}$ for tensile strength and Young's modulus, respectively.

The result of water absorption shown in Figure 9 indicates the highest value obtained by the $3-\mathrm{D}$ type which is at $6 \%$ and the lowest value is woven type with $4 \%$. This again concluded of similar findings that $3 \mathrm{D}$ glass fibre can retain large amount of water due to the presence of empty space or void in between their surfaces and in middle body as shown in Figure 10(a). This allows water to accumulate in the voids and stays there. 


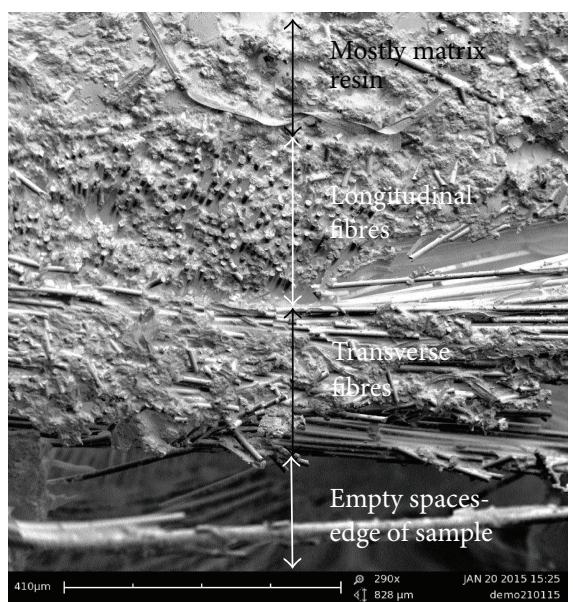

(a)

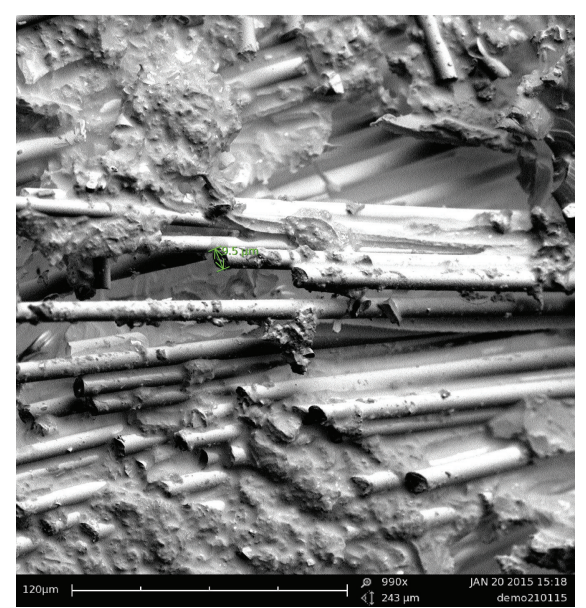

(b)

FIGURE 11: SEM micrograph of hybrid GFRP at (a) 290x (b) 990x.

On the other hand, woven has the best performance to avoid water absorption. This is due to the fact that woven structure has small amount of void or empty space as illustrated in Figure 10(b). Furthermore, woven has compacted structure compared to 3D type [15]. Thus, water requires more time or pressure to absorb water into its structure. The chopped type does not have a structure or shape like 3D. It is just strands of fibre and mixed randomly into the matrix.

3.4. Micrographs. Micrographs of the hybrid GFRP fracture surface were captured using scanning electron microscope (SEM). Fracture surface usually indicate the mode of fracture of the sample. Figure 11 indicates the cross section of tensile hybrid GFRP fracture surface.

Micrograph at lower magnification of 290x is shown in Figure 11(a). It was found that at the lower region of the micrograph is the sample's edge followed by the mixture of fibre arrangement, transverse and longitudinal. Above the longitudinal layer is a region of mostly matrix resin which most likely belongs to the chopped fibre since chopped fibre was added in random order.

Higher magnification micrograph at $990 \mathrm{x}$ is shown in Figure 11(b). It was discovered that there is sign of fibre pull out. The diameter of the fibre measured is $9.5 \mu \mathrm{m}$. In general, both micrographs show rough fracture surface which indicate ductile failure.

\section{Conclusions}

The mechanical and physical behaviour of hybrid glass fibre reinforced plastic (GFRP) was studied. There are three different types of materials, namely $3 \mathrm{D}$, woven, and chopped fibre types, which were blended with the mixture of polyester and hardener. The hybrid GFRP was investigated by varying three parameters which were volume fractions $(0.0 \%$ to $0.5 \%$ ), hybrid GFRP fibre arrangement and types of glass fibre in each layer. The hybrid GFRP was fabricated by hand lay-up process. Three types of tests were conducted such as tensile for strength and modulus, water absorption, and hardness tests. The volume fraction of $0.5 \%$ gives the highest value in all testings. The tensile strength of $0.5 \%$ is $73 \mathrm{MPa}$ and modulus value is $821 \mathrm{MPa}$. The arrangement of choppedwoven-3D-woven-chopped gives the highest strength of $66 \mathrm{MPa}$ and woven-chopped-woven-chopped-woven gives the highest stiffness as well as the lowest water absorption of $4.5 \%$. Among the single type, woven gives the highest value of both strength and stiffness of $51 \mathrm{MPa}$ and $538 \mathrm{MPa}$, respectively. The highest value of hardness was found for 0.5 volume fraction at 35 shore durometer-D.

\section{Conflict of Interests}

The authors declare that there is no conflict of interests regarding the publication of this paper.

\section{References}

[1] I. Shyha, "An investigation into $\mathrm{CO}_{2}$ laser trimming of CFRP and GFRP composites," Procedia Engineering, vol. 63, pp. 931937, 2013.

[2] M. Baena, A. Turon, L. Torres, and C. Miàs, "Experimental study and code predictions of fibre reinforced polymer reinforced concrete (FRP RC) tensile members," Composite Structures, vol. 93, no. 10, pp. 2511-2520, 2011.

[3] M. Moravčík, P. Kotula, and F. Bahleda, "Experimental and FEM analysis of hybrid composite structures with GFRP elements," Procedia Engineering, vol. 40, pp. 268-273, 2012.

[4] G. Kretsis, "A review of the tensile, compressive, flexural and shear properties of hybrid fibre-reinforced plastics," Composites, vol. 18, no. 1, pp. 13-23, 1987.

[5] A. Singh Saroya and V. Meena, Study of mechanical properties of hybrid natural fiber composite [B.Tech thesis], National Institute of Technology Rourkela, Rourkela, India, 2011.

[6] R. J. Muhi, F. Najim, and M. F. S. F. De Moura, "The effect of hybridization on the GFRP behavior under high velocity impact," Composites Part B: Engineering, vol. 40, no. 8, pp. 798803, 2009. 
[7] L. A. P. de Oliveira and J. P. Castro-Gomes, "Physical and mechanical behaviour of recycled PET fibre reinforced mortar," Construction and Building Materials, vol. 25, no. 4, pp. 1712-1717, 2011.

[8] D. Foti, "Preliminary analysis of concrete reinforced with waste bottles PET fibers," Construction and Building Materials, vol. 25, no. 4, pp. 1906-1915, 2011.

[9] D. Foti and S. Vacca, "Mechanical behavior of concrete columns reinforced with rheoplastic mortar," Materiales de Construccion, vol. 63, no. 310, pp. 267-282, 2013.

[10] A. Danladi and J. Shu'aib, "Fabrication and properties of pineapple fibre/high density polyethylene composites," American Journal of Materials Science, vol. 4, no. 3, pp. 139-143, 2014.

[11] Z. Salleh, N. A. Nordin, and I. Saad, Comparison of Mechanical Properties for Polypropylene (PP), Laminated on Fiberglass/Epoxy Resin and Aluminium Net/Epoxy Resin Composites, Institute of Research, Development and Commercialisation, 2002.

[12] D. Hull and T. W. Clyne, An Introduction to Composite Materials, Cambridge University Press, Cambridge, UK, 1996.

[13] A. Abdullah, D. Hussein Rusel, and A. Abdulwahab, "Water absorption and mechanical properties of high-density polyethylene/egg shell composite," Journal of Basrah Researches (Sciences), vol. 37, no. 3, pp. 36-42, 2011.

[14] T. M. Malik, P. J. Carreau, H. P. Schreiber, A. Rudin, L. Kale, and W. Tchir, "Property stabilization in filled, drawn polyethylene," Journal of Applied Polymer Science, vol. 43, no. 3, pp. 543-551, 1991.

[15] D. Taylor, An evaluation of 3D woven orthogonal composites' potential in the automotive supply chain [Ph.D. thesis], NC State University, Raleigh, NC, USA, 2013.

[16] Eric Greene Associates, Composites Design and Manufacture (BEng)-MATS 324 Core materials for sandwich panels, 2003.

[17] Q. Abdulah Abas, "Effect of water absorption on impact strength for epoxy-glass fibers composite," Journal of University of Anbar for Pure Science, vol. 5, no. 2, 2011. 

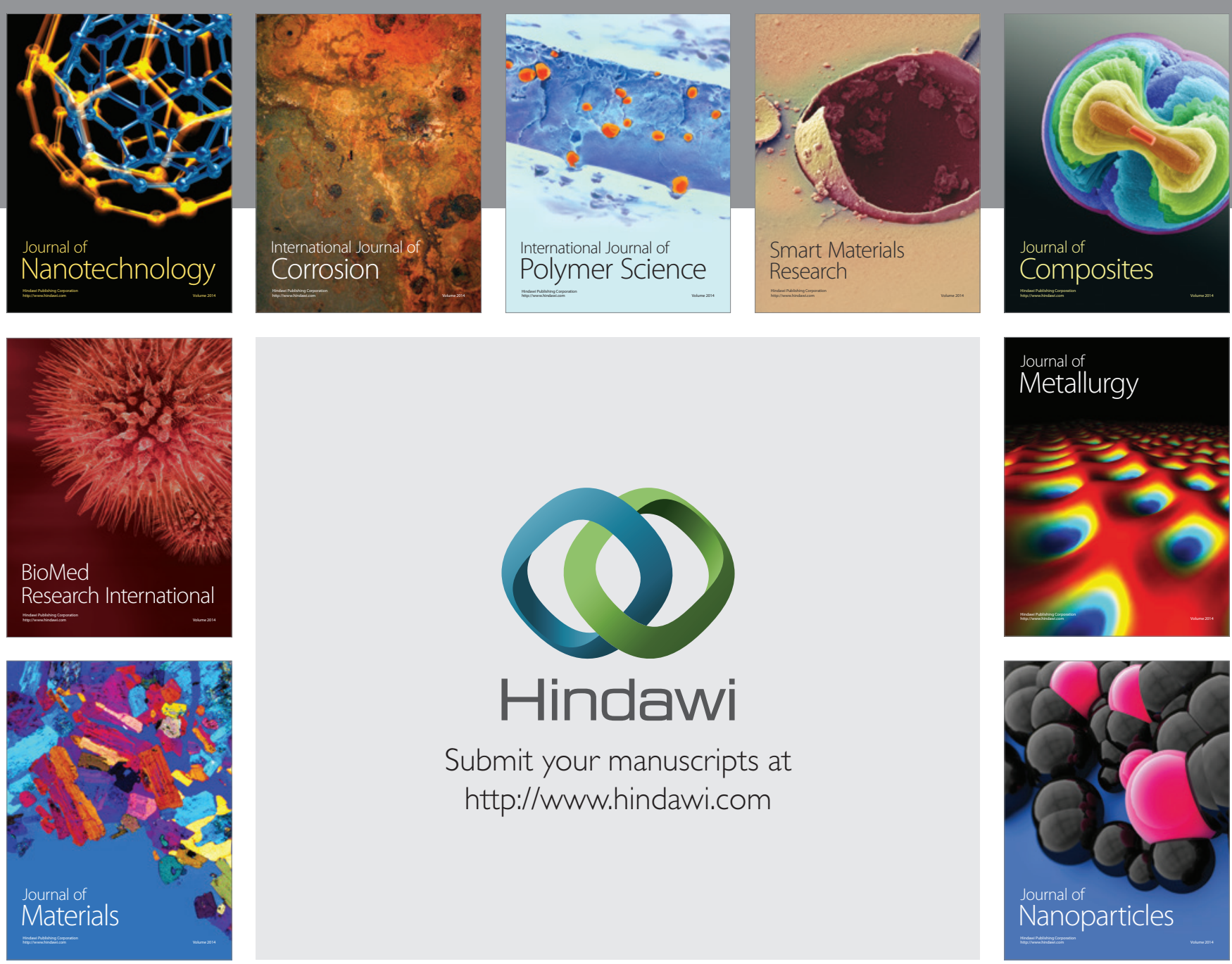

Submit your manuscripts at http://www.hindawi.com
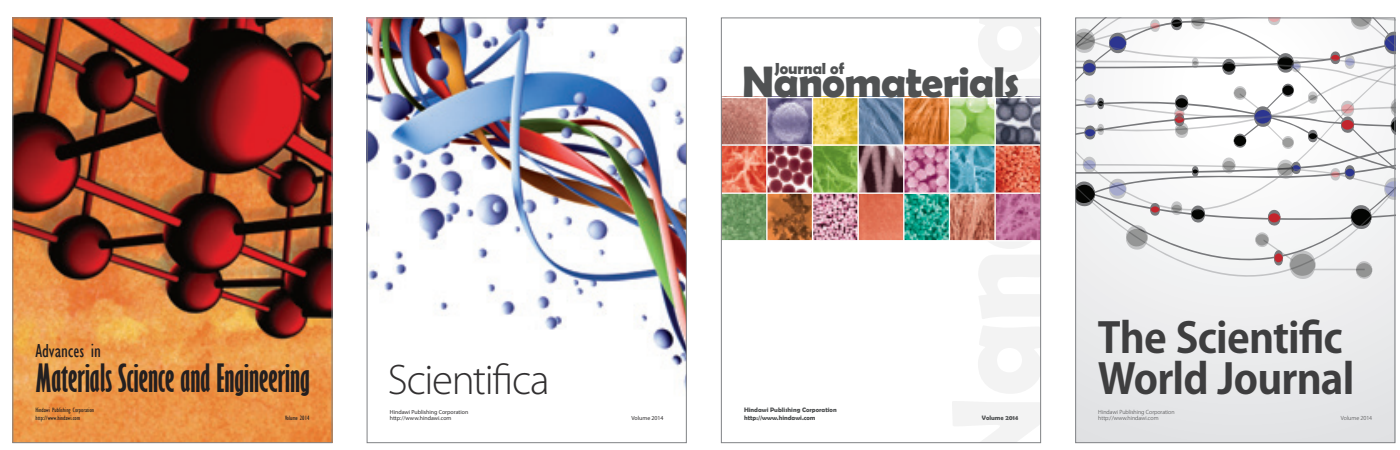

\section{The Scientific World Journal}
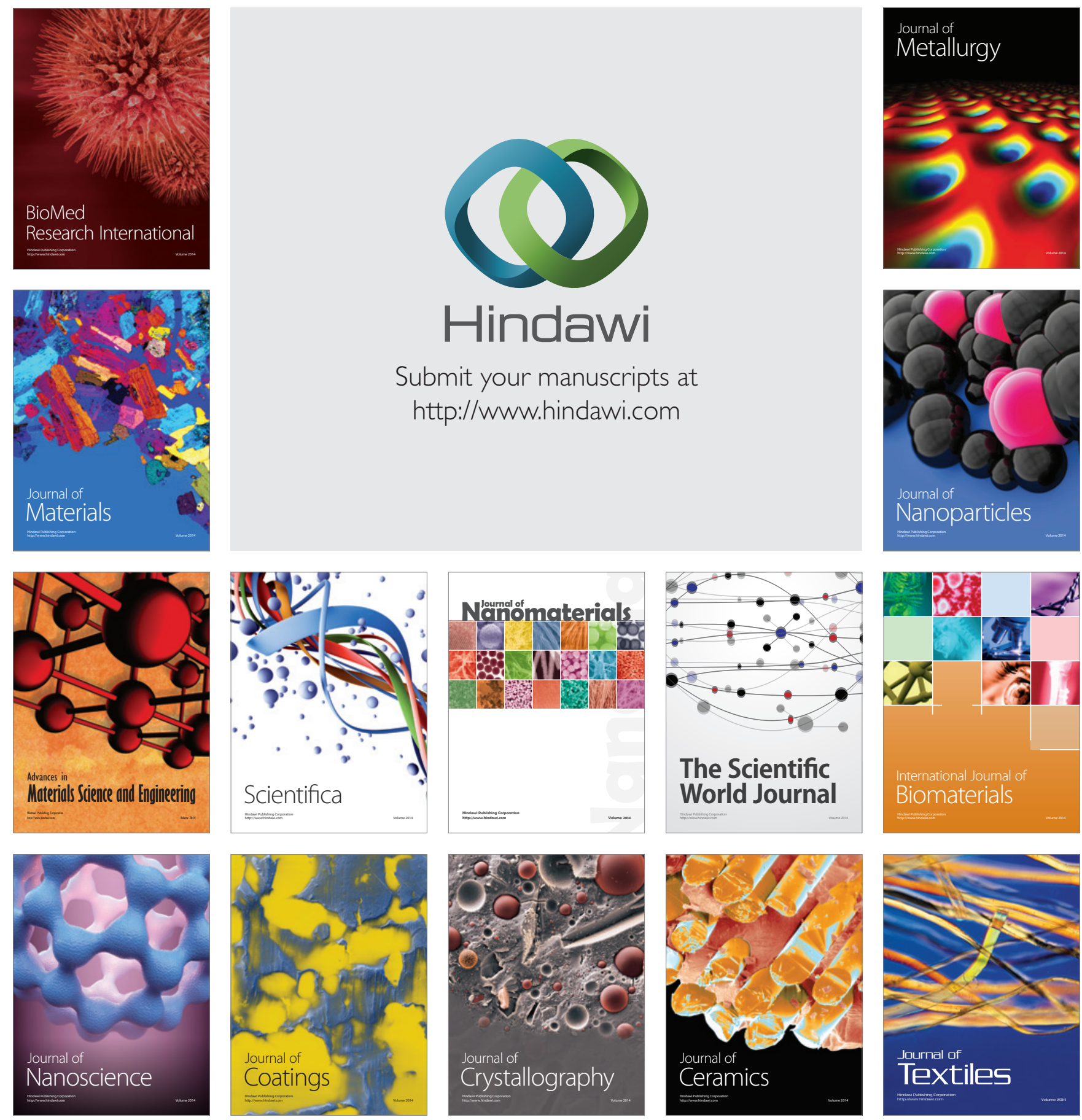